ISSN 1112-9867

Available online at http://www.jfas.info

\title{
DETERMINING A PISTON'S TOP DEAD CENTER (TDC) IN AN AUTOMOBILE USING INSTALLED PIEZOELECTRIC ON A VIBRATING BEAM
}

\author{
M. Mahmoudi ${ }^{1, *}$, F. Vatankhahan ${ }^{2}$, M.H. Totian ${ }^{3}$, A. Fouladgar ${ }^{4}$, A. Ghassemi ${ }^{5}$
}

${ }^{1}$ B.Sc. Student, in Azad University Central Tehran Branch, Iran

${ }^{2}$ B.Sc. Student, in Islamic Azad University, Najafabad Branch, Iran

${ }^{3}$ B.Sc. Student, in Islamic Azad University of Isfahan, Iran/ Department of Civil Engineering

${ }^{4}$ B.Sc. Student, in University of Shahreza, Iran/ Department of Mechanical Engineering

${ }^{5}$ Assistant Professor in Islamic Azad University, Najafabad Branch, Iran

Published online: 15 May 2016

\begin{abstract}
Smart structures and MEMS are considered important field recently, due to the importance and high capabilities in measurement and the power of reaction and response to changes of the surroundings. This research concerns two fields of practical vision in the automotive industry and discuss the energy recycled industrial vibrations. The goal is to use the PVDF piezoelectric elements in car flywheel for energy harvesting, and compare and replace it with the revolution sensor. This research is totally based on empirical tests data and the result that the use of piezoelectric polymer sensors can harvest energy, was find performing far better than inductive sensors.
\end{abstract}

Keywords: Piezoelectric element; Vibration energy harvesting; smart structures; Revolution sensor; Flywheel.

Author Correspondence, e-mail: author@gmail.com

doi: http://dx.doi.org/10.4314/jfas.v8i3s.17 


\section{INTRODUCTION}

Flywheel acts between the engine and car gearbox where main tasks of the flywheel; are eliminate motor vibration, adjust the speed of crankshaft at different RPMs, save the explosive force of combustion, and transmission it to the crankshaft in time of need, and it's also is one of the power transmission parts [1]. The revolution sensor is located above the flywheel [2], and its job is calculation of the time of ignition, calculation and diagnosing engine mods, notification to injector system and fuel injection operation into the car cylinders [2]. The purpose of this article (Fig. 9) is energy harvesting of the flywheel, by using piezoelectric elements in type of PVDF, and replacement and comparing the performance of this element with revolution sensors. This comparison, is quite experimentally tested and the results have shown that replacing the sensor, in addition to electrical energy harvesting [3], is performing much better than inductive revolution sensors where its advantages are the signals sent to the ECU very easily and accurately processed. These factors cause the engine at high speeds more regular work so error and failure does not occur during sending commands to the injector system [4] this mechanism consists of a cantilever beam [5] with a piezoelectric element attached $[5,6]$ to it, and against the flywheel teeth are placed under high mechanical vibration [1] A method is using piezoelectric on beams under vibration [5] is an issue that has recently attracted the attention of researchers, in most of these studies, researchers have tried to reduce the amplitude of oscillations and increase the vibration $[3,7]$ beams so that they can get more energy from the piezoelectric save, for example, using a magnetic field [8] , electromagnetic induction $[9,10]$ hit [11], increasing the elasticity of the beam [12] and etc. The proposed scheme vibrations with very low amplitude vibration is automated and does not require quite the way applications are used in automotive and energy.

\section{HOW INDUCTION REVOLUTION SENSOR WORKS}

Automotive revolution sensor has four duties [2] that were mentioned in the introduction. Here, we want to check that this is precisely how the sensor sends information to the ECU and ECU how to realize what a moment, for example, piston number one is on the upper death point, and respective injector gives command of the fuel injection. In Fig. 2 it is seen that this 
sensor is above the vehicle's flywheel teeth [2]. The flywheel has 60 teethes, according Fig. 2 two tooth is flat, and it is made of alloy steel [1]. The sensor works according to electromagnetic induction law. When the vehicle engine is turned on, and the flywheel begins to rotate, the flywheel teeth passes the front sensor. There is a coil in the internal structure of the sensor that with each passing stage in front of the coil (Fig. 2), an electrical pulse is induced in it, and ipso facto, a pattern signal [2] is released and sent to ECU automatically. When the area in flywheel is placed against the coil, the current induced will not be in it. An interruption occurs in the production signal process. Car Engine sets that it occurs when the piston is at top dead center (TDC). When ECU finds out interrupt signal it will issue a command injection to injector number one.

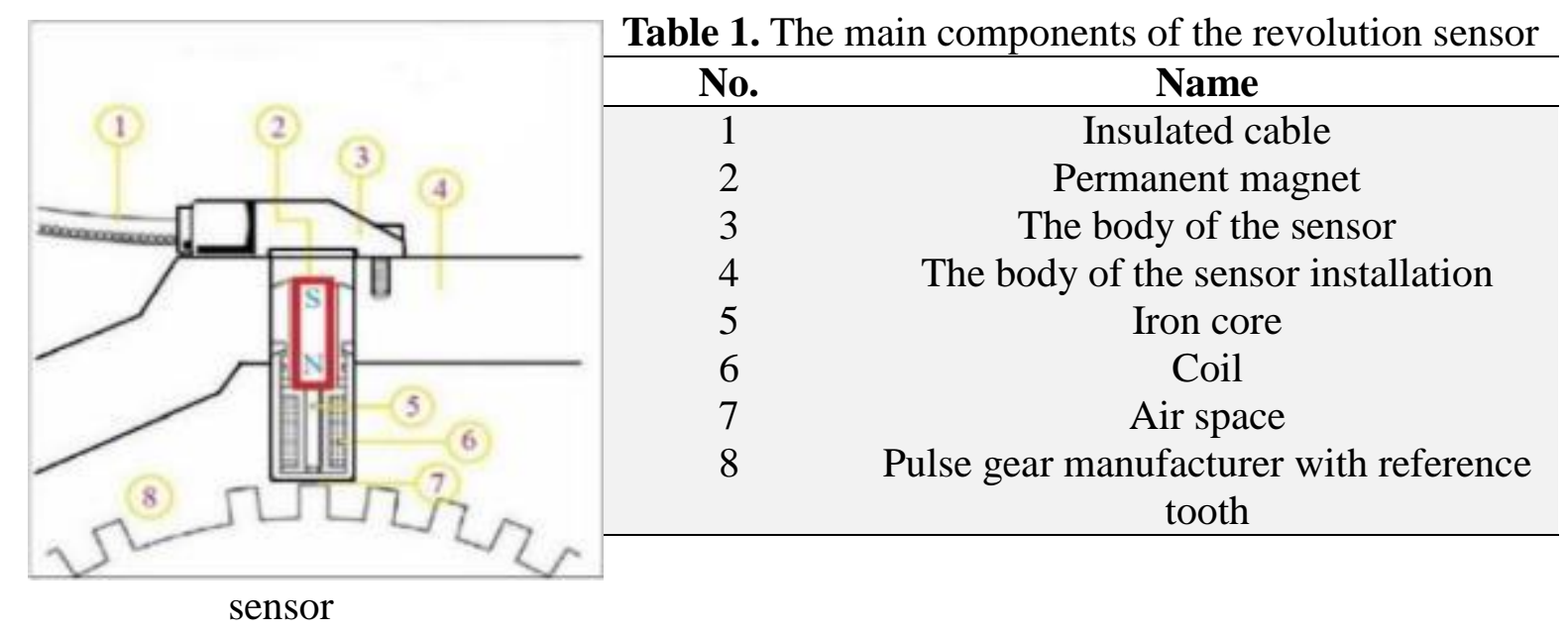

According to Fig. 2 this method has high noise and ramps. Two flywheel teeth are removed, because in the course of this interruption as well as with other high signal is not detected. For this reason a supported sensor have been used on the engine camshaft (Fig. 3) so at the same time, this sensor sends the information to the ECU to finally work carefully (Fig. 3). (This signal pattern is taken by Iran Khodro). 


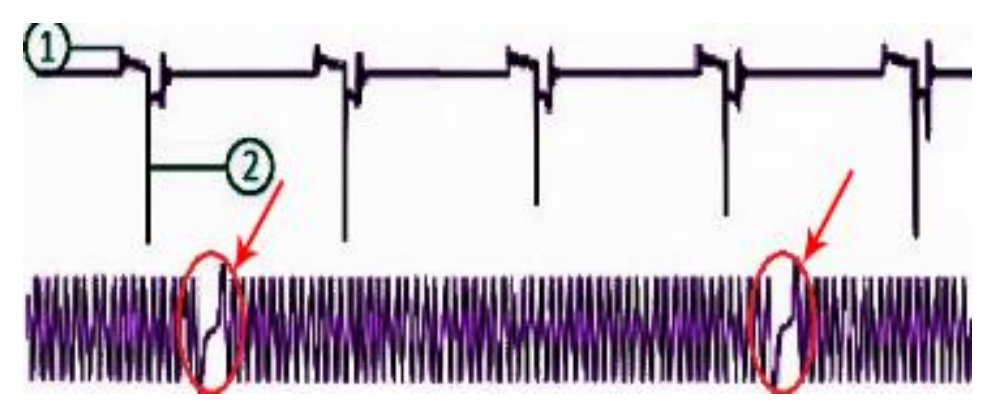

Fig. 2. Signal pattern generation of inductive sensors for XU7 engine. Number 1 is the noise and errors and number 2 has interrupted in the process signal generated that is in the bottom pattern with the red arrow is visible.
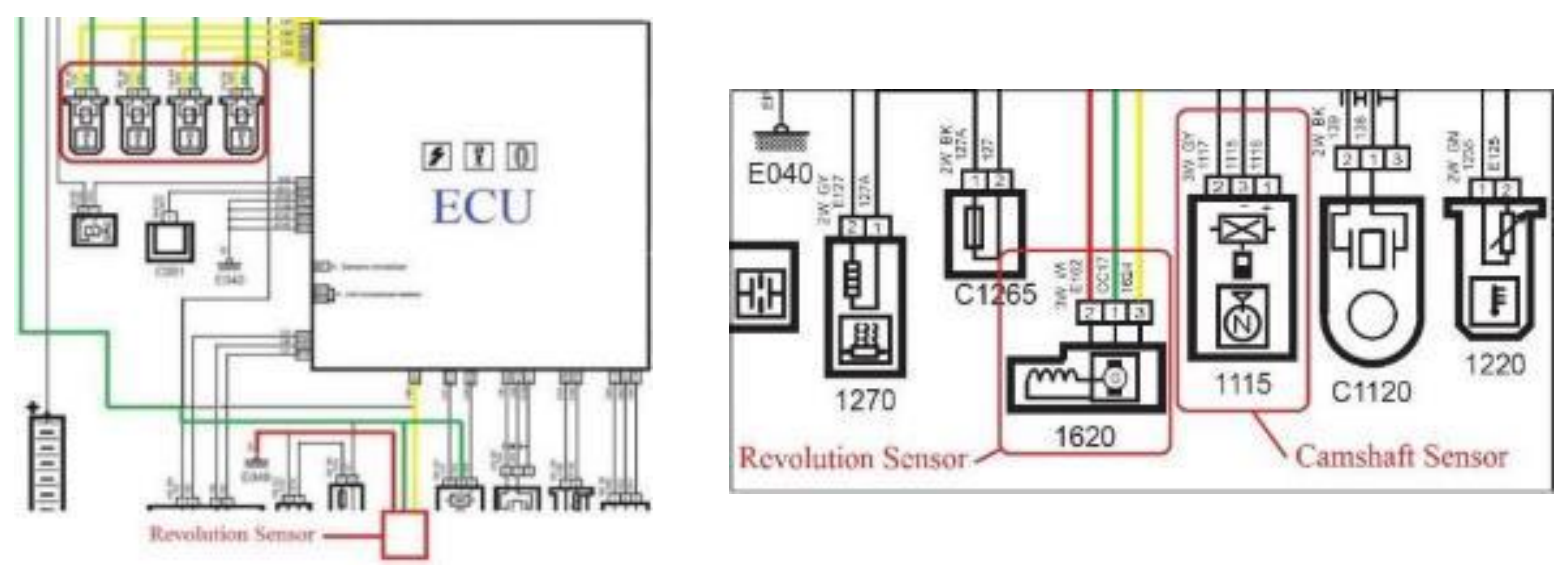

Fig. 3. Revolution sensor send data to ECU and ECU analysis these, then forward to injectors and injection fuel operation performed as repeated. Injection fuel operation for Four-cylinder engine. ECU Forward signal to injector for injection fuel respectively and regular. Camshaft sensor is backup for revolution sensor.

Distance of coil to the teeth is $0.2-1 \mathrm{~mm}$ that over time this distance will be decreased, and signal changes due to grease and dirt and do not reach good and with care to the ECU (Fig. 1). So the car at high speeds can malfunction and or injectors system in the fuel injection malfunction and fuel burn as raw (Fig. 3).

\section{PRESENTATION AND SIMULATION DESIGN}

As seen in Fig. 4, the piezoelectric elements connected on a fixed beam and end of the beam is front of the flywheel teeth. Thus, with rotation of flywheel, beam vibrated and the piezoelectric element 
vibrates with the same frequency shows a pattern of voltage changes [5, 12]. Finally, the output of piezoelectric, shall be compared with the revolution sensor (Fig. 2).
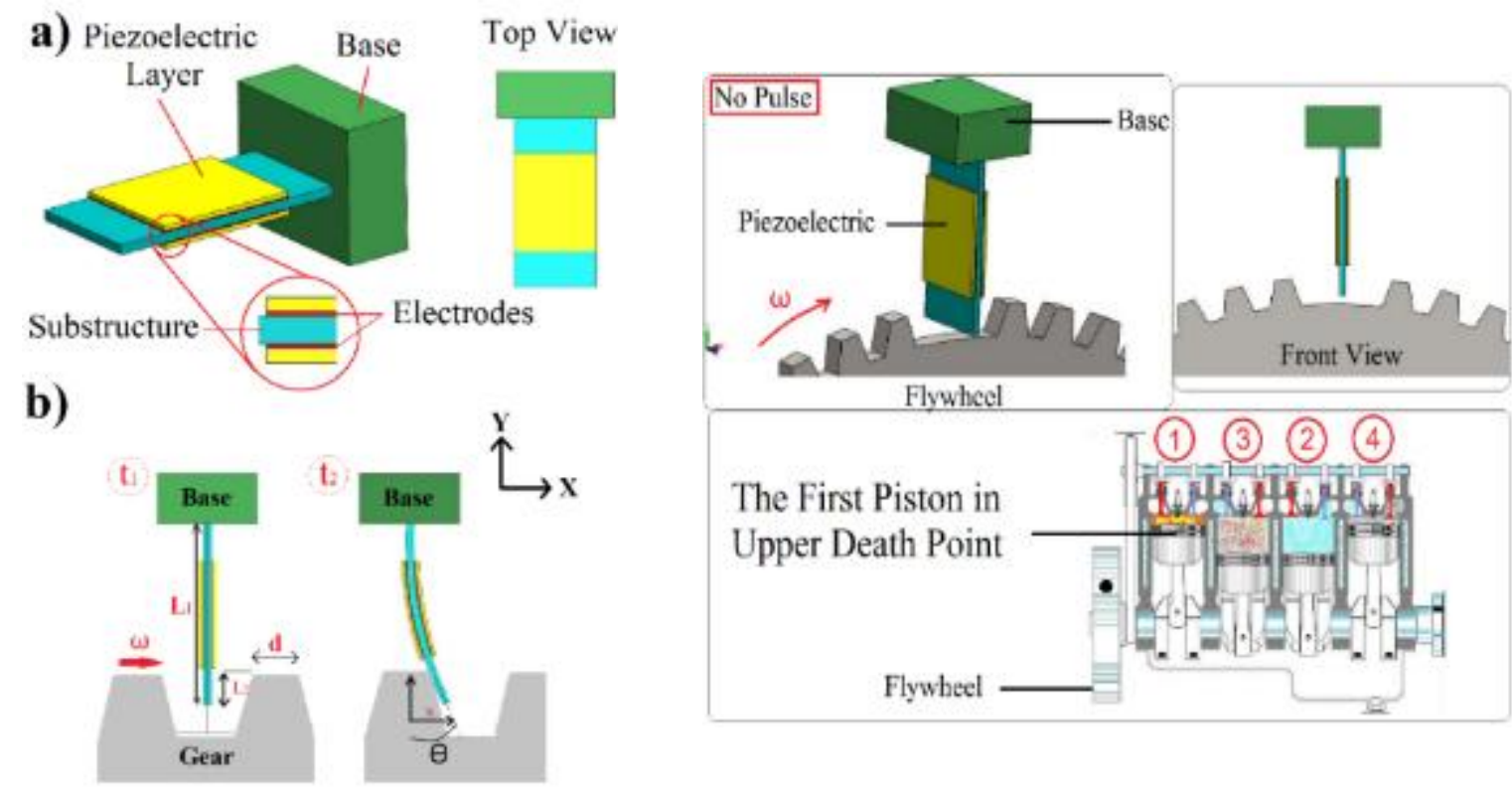

Fig. 4. In the picture (a) schematic view of the proposal was given which includes a cantilever, two piezoelectric elements with electrodes. In part (b), two-dimensional view of the vision face in the moments before the collision $\boldsymbol{t} \mathbf{1}$ And a moment hitting the flywheel by the end of the beam $\mathbf{t} 2$ is shown. In continuation next of the design, size of $\mathrm{L}, \mathrm{w}$ and $\mathrm{x}$ is given in detail.

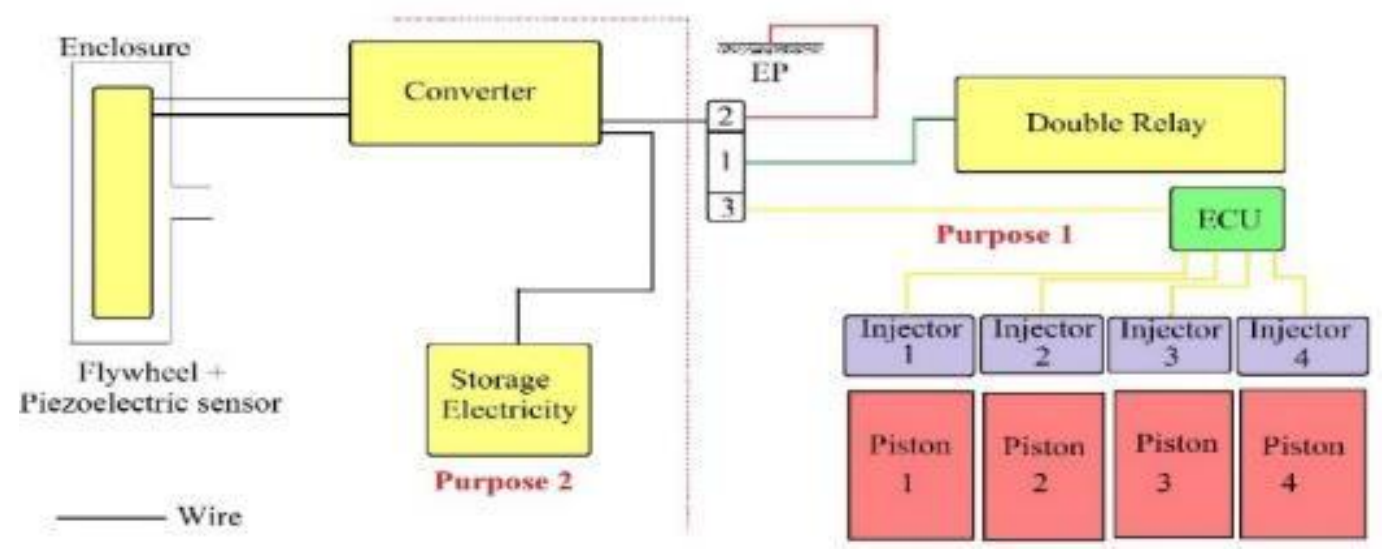

Fig. 5. The two main objectives of the piezoelectric: 1. Energy harvesting and storage of electricity 2. Perform all tasks that inductive revolution sensors does.

To implement these objectives, one test as testable, matching with Fig. 6 and 7, was simulated 
and made. In this test, the electric motor with speed of 900RPM and $50 \mathrm{~Hz}$ frequency is used instead of car engine and instead of a round aluminum flywheel milling accordance with the motor shaft and the size of the car flywheel is used. A structure has been designed to tie up beam and piezoelectric.
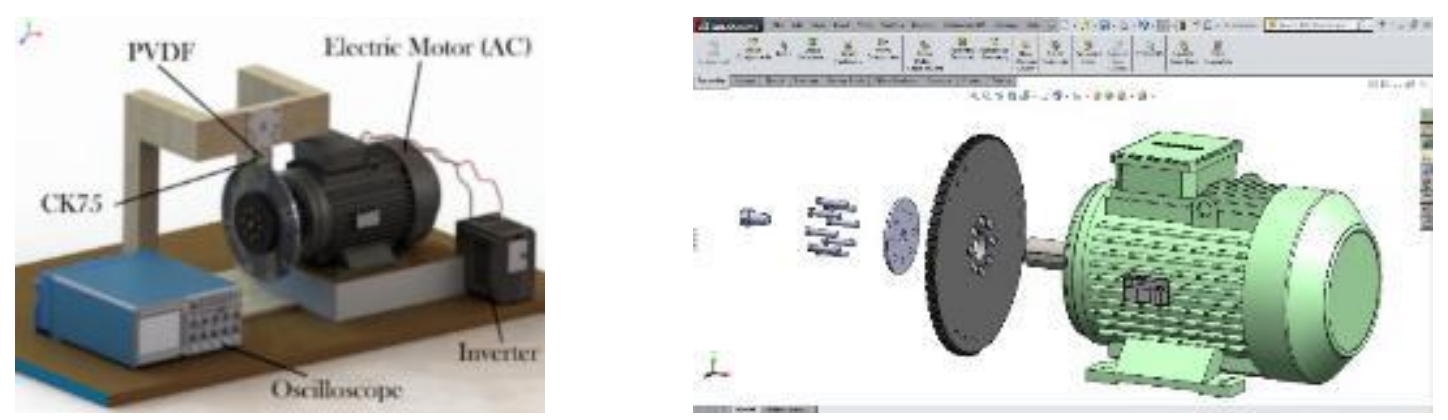

Fig. 6. Final design and simulation of mechanism components before the construction phase

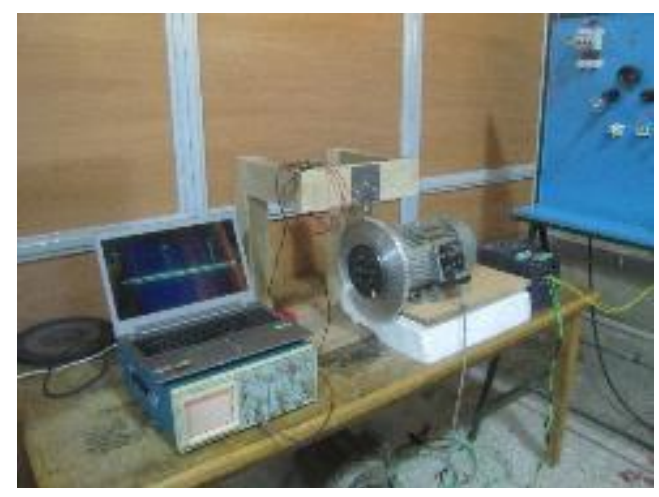

$\mathbf{a}$

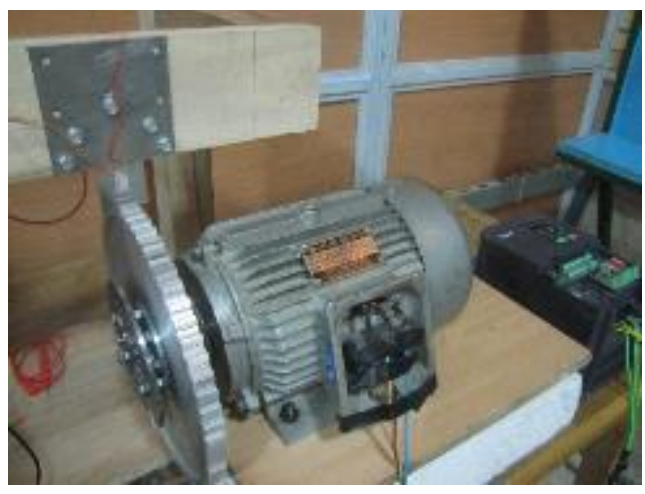

b

Fig. 7. (a) Electric motor, three-phase electricity is fed and the flywheel on the motor shaft is fixed thorns by means of thorns, bolts and spur. Piezoelectric output before entering the oscilloscope, will enter orbit and voltage versus time graph is visible. (b) The base engine is fixed on board the wooden by bolts and in ways that minimize vibrations have been balance.

Below the base of the timber, the foam layers is used to adjust the height of the engine to the beam, somehow that gear teeth engage with beam is $1 \mathrm{~mm}$. The design is such that all sizes can be changed easily. The beam has been raised as much as possible to minimize stress and displacement beam (Fig. 7). 

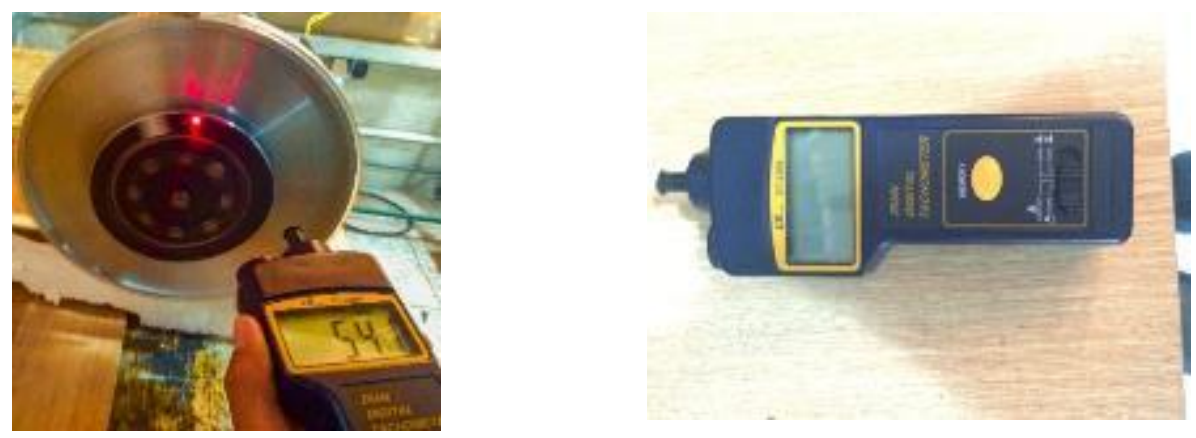

Fig. 8. Inverter device and laser tachometer, to adjust the engine speed is used. A reflecting laser tag located on the flywheel. Inverter on the one hand input of the engine and on the other to the three-phase is connected. The relationship Between the Frequency inverter and motor to a linear relationship. The test started of 30 RPM to 400 RPM and calculated. As you can see around $400 \mathrm{RPM}$ equivalent to $20 \mathrm{~Hz}$.

\subsection{Beam design}

Since the piezoelectric will be connected the beam and piezoelectric vibrates, so that we need the beam to be able to resist the test conditions (400RPM). The beam was designed according to dynamic FEM simulation. According to FE results the maximum stress eserted to the beam in 400RPM is approximately 1200Mpa. Accordingly, we chose CK75 the spring steel with yield strength of 1275MPa. Fig. 9, 11 show the results.

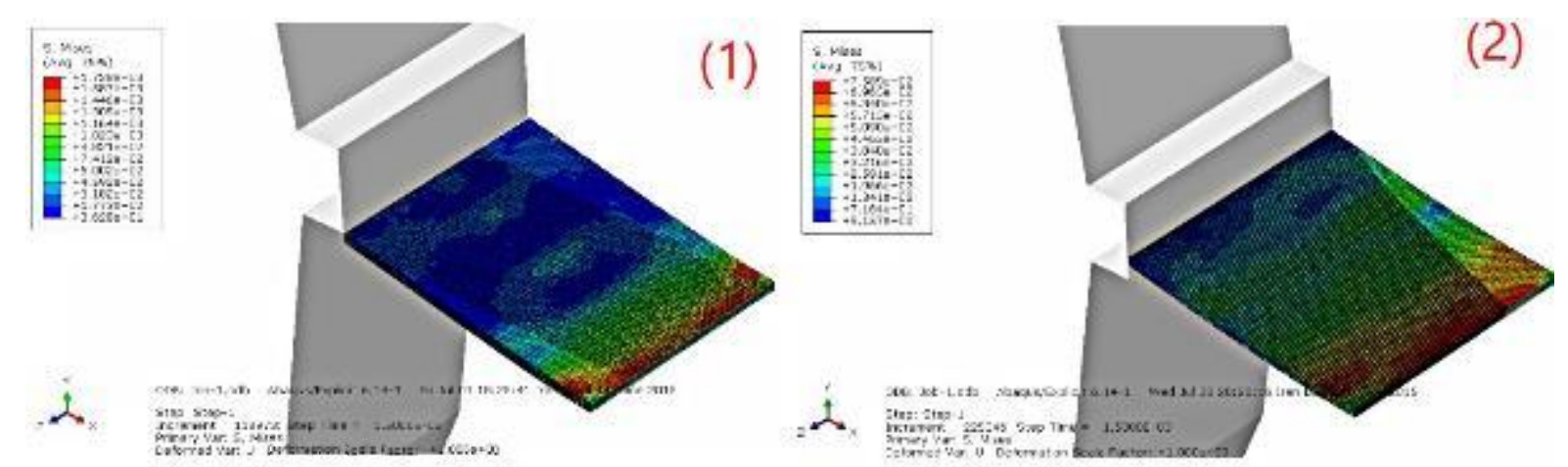

Fig. 9. Dynamic analysis of beams (FEM simulation). In the analysis of (1) CK45 beam with dimensions $40 \boldsymbol{r} \boldsymbol{n} \times \mathbf{5 0 n} \boldsymbol{n}$ and thickness of $1 \mathrm{~mm}$ is considered. After loading hit the flywheel teeth, the tension has gone up and the beam of elastic to plastic is gone. In the analysis, (2) reduce the beam size of $10 \mathrm{~mm}$ and the material CK75, reduced tension in the beam as much as possible. 
According to the results the stress is not to the extent that bar undergoes plastic mode.

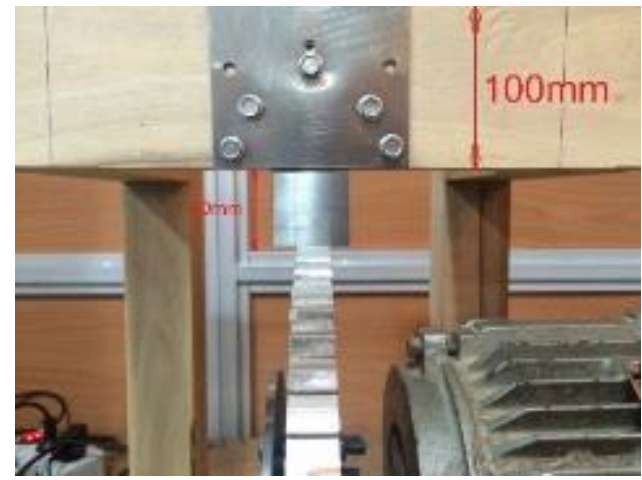

Fig. 10. How to deal flywheel teeth with end of the beam

In Fig. 10, the flywheel coupling with the motor shaft and tying it has been shown. Beam is easily replaceable. Motor counterclockwise direction and beam height by caliper has been considered.

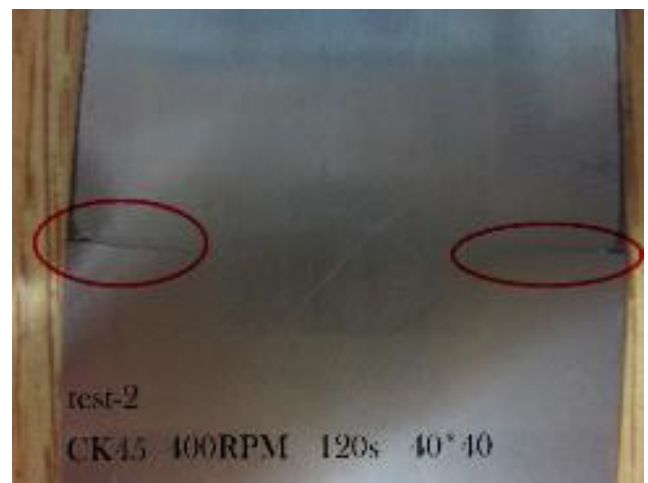

(1)

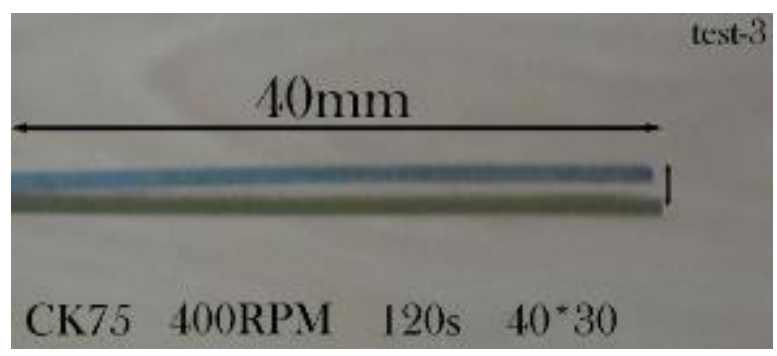

(2)

Fig. 11. (1) As expected loading conditions, not tolerating CK45 sheet and place the beam in clamp was fixed, failure and lost their elastic properties. This test speed 400RPM and the time was 120 seconds. (2) Picture a) is for (1) .In this picture you can well-observed and compared that who bended the sheet than normal state. The displacement of about $7 \mathrm{~mm}$. Image (b) is for CK75 with dimensions of $\mathbf{4 0} \boldsymbol{n} \boldsymbol{n} \times \mathbf{4 0} \boldsymbol{n} \boldsymbol{n}$ in situations with 400RPM speed and duration of 300 seconds has endured. (The curvature that you can see is of the pre-test and when the cut sheet)

Considering analysis, calculations and tests results in use of CK75 sheet size of $10 \mathrm{~mm} \times$ $40 \mathrm{~mm} \times 40 \mathrm{~mm}$ use. (All beams have been prepared cut by WEDM and with very high precision) 
Table 2. Profile of spring steel CK75 (DIN) - AISI 1075

\begin{tabular}{cccc}
\hline Title & \multicolumn{2}{c}{ CK75 } & Unit \\
\hline Density & \multicolumn{2}{c}{7.85} & $\mathrm{~g} / \mathrm{cm}^{3}$ \\
Yield Stress & \multicolumn{2}{c}{1275} & $\mathrm{~N} / \mathrm{mm}^{2}$ \\
Tensile Stress & \multicolumn{2}{c}{$1320-1870$} & \\
\cline { 2 - 3 } Chemical & $\mathrm{C}$ & 0.75 & \\
Composition & $\mathrm{Si}$ & 0.25 & \multirow{2}{*}{ in weight $\%$} \\
& $\mathrm{Mn}$ & 0.70 & \\
\hline
\end{tabular}

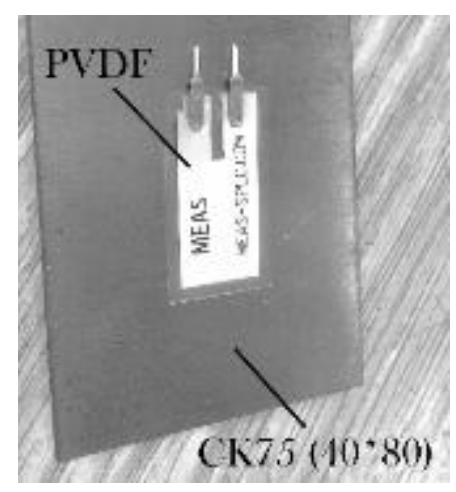

Fig. 12. Connecting PVDF on CK75 sheet with dimensions of $40 \times 80 \times 1 \mathrm{~mm}$. $40 \mathrm{~mm}$ Is inserted into the clamp and the connection will be temporary. Piezoelectric is connected to the beginning of the beam so do not be vibrating piezoelectric port. (If these port are under vibrating, the pattern signal is generated by along with the error)

Table 3. Main specifications of PVDF

\begin{tabular}{|c|c|c|c|c|}
\hline Symbol & Parameter & PVDF & Copolymer & \multirow{2}{*}{ Unit } \\
\hline $\mathrm{d}_{3 .}$ & \multirow[b]{2}{*}{$\begin{array}{c}\text { Piezo } \\
\text { Strain Constant }\end{array}$} & 23 & 11 & \\
\hline $\mathrm{d}_{33}^{\mathrm{it001}}$ & & -33 & -38 & $10_{-12} \frac{\mathrm{c} / \mathrm{m}^{2}}{\mathrm{~N} / \mathrm{m}^{2}}$ \\
\hline$g_{ \pm 1}^{3: 3}$ & \multirow{2}{*}{$\begin{array}{c}\text { Piezo } \\
\text { Stress Constant }\end{array}$} & 216 & 162 & \multirow{2}{*}{$10 \frac{\mathrm{V} / \mathrm{m}^{2}}{\mathrm{I}} 10_{-3} \frac{\sqrt{\mathrm{m}}}{\sqrt{/ \mathrm{m}^{2}}}$} \\
\hline$g_{31}$ & & -330 & -542 & \\
\hline $\mathrm{k}_{3.2}^{3}$ & \multirow{2}{*}{$\begin{array}{l}\text { Electromechanical } \\
\text { Coupling Factor }\end{array}$} & $12 \%$ & $20 \%$ & \\
\hline $\mathrm{k}^{-}$ & & $14 \%$ & $25-29 \%$ & \\
\hline $\mathrm{C}$ & Capacitance & 380 for $28 \mu$ & 68 for $100 \mu$ & $\mathrm{pF} / \mathrm{cm}^{2} @ 1 \mathrm{~K}$ \\
\hline $\mathrm{Y}$ & Young's Modulus & $2-4$ & $3-5$ & $10^{\mathrm{n} 2} \mathrm{~N}^{-1 \mathrm{KHz}}$ \\
\hline$\varepsilon$ & Permittivity & $106-113$ & 40 & $10_{-12 \mathrm{~N} / \mathrm{m}}^{19}$ \\
\hline$\rho$ & Mass Density & 1.78 & 1.82 & $10 \frac{-12}{\mathrm{k}} \frac{\mathrm{gm}^{2} / \mathrm{m}}{/ \mathrm{m}}$ \\
\hline
\end{tabular}


PVDF is a type of piezoelectric, with polymerization properties unlike ceramic PZT species. It has high flexibility, and the polarization direction is in 3 directions. (Fig. 13.2)

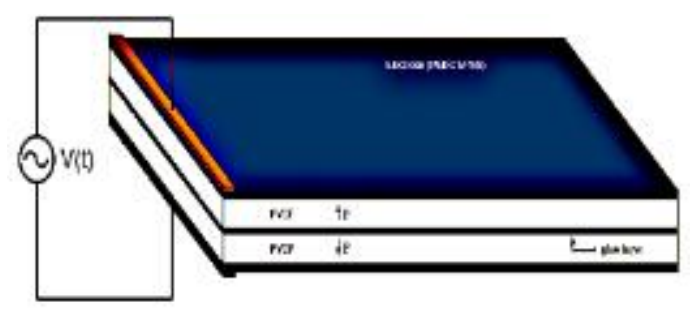

(1)

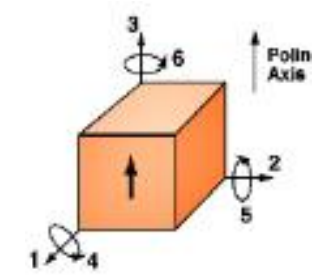

(2)

Fig. 13. (1) Schematic of a bimorph and (2) Axis notation for polarized piezoelectric ceramics

\section{RESULTS AND DISCUSSION}

\subsection{Check of similar functions of this mechanism with induction sensor}

After the tests were performed on piezoelectric, the results are as follows: All images are capture at 60 frames per second and as long as the engine does not work, there is no voltage and voltage variations versus time graph, will be a horizontal line. (Fig. 18)
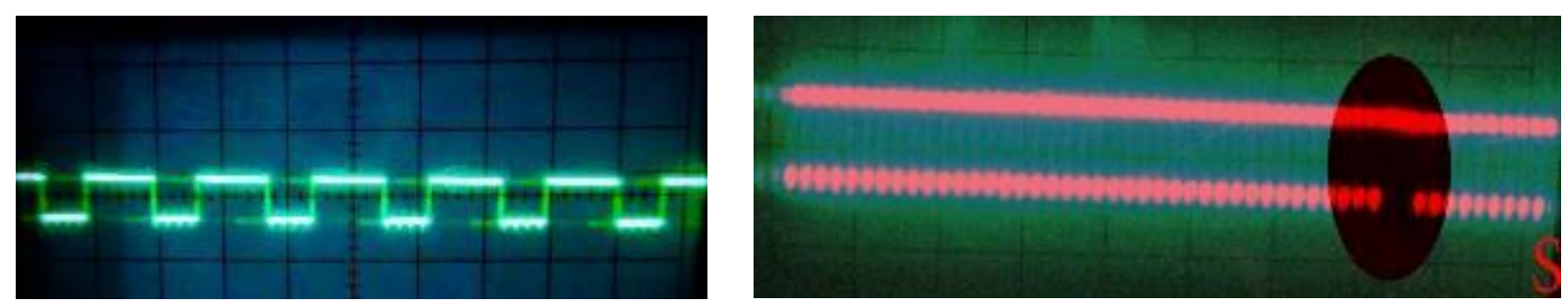

Fig. 14. Result of the PVDF output by speed 600RPM. The left image, pulse that has been created, because a portion of that two-tooth flywheel is flat. In the right image, with the changes that have been made in oscilloscope, otherwise the interrupt signal is marked with red circle.

In Fig. 14, the right image, a simple cycle of rotation of the flywheel is shown. In part that is marked with a red circle as well as two flat teeth that are visible. Difference "S" in this image has happened because in fact pulses are not square and have created a slight angle. The cycle is shown in Fig. 15, this difference has occurred, but because the engine speed is 400 RPM this difference is more clearly seen. (At higher engine speeds the difference is almost zero) 


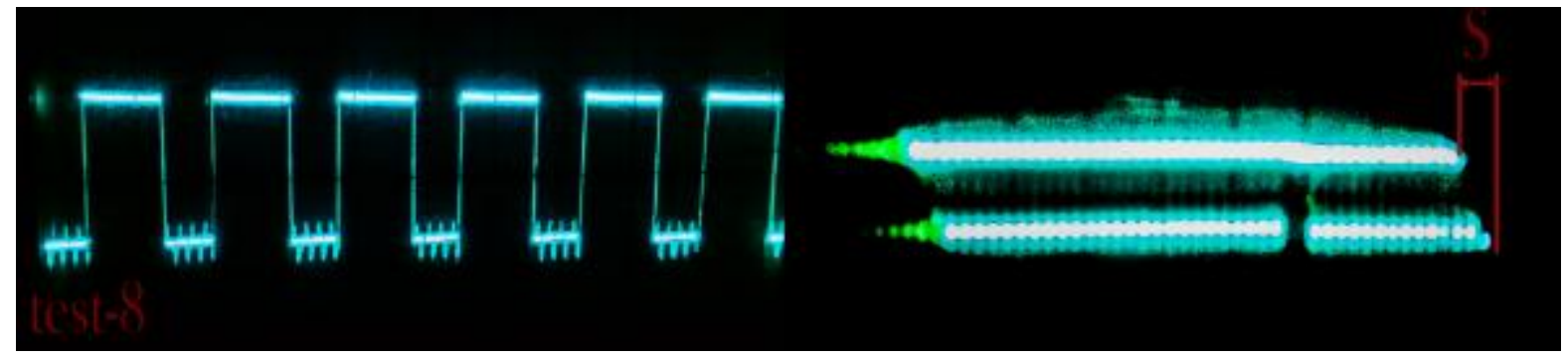

Fig. 15. Diagram voltage - time. Output of PVDF in speed 400RPM

As seen, period fluctuations from 600RPM to 400RPM in engine speed, is a bit higher. In Fig. 17 , the angle at which the pulses output from the piezoelectric is shown.

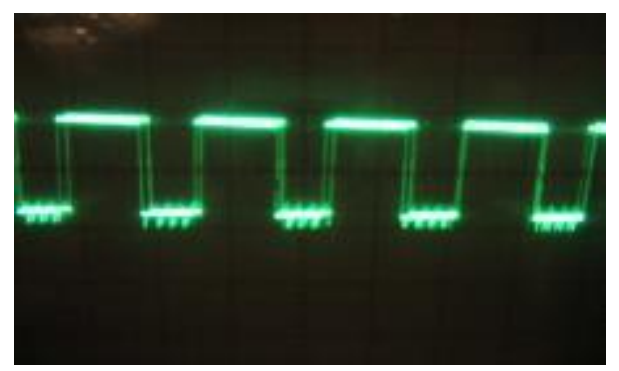

Fig. 16. Diagram voltage - time .Output of PVDF in speed 300RPM

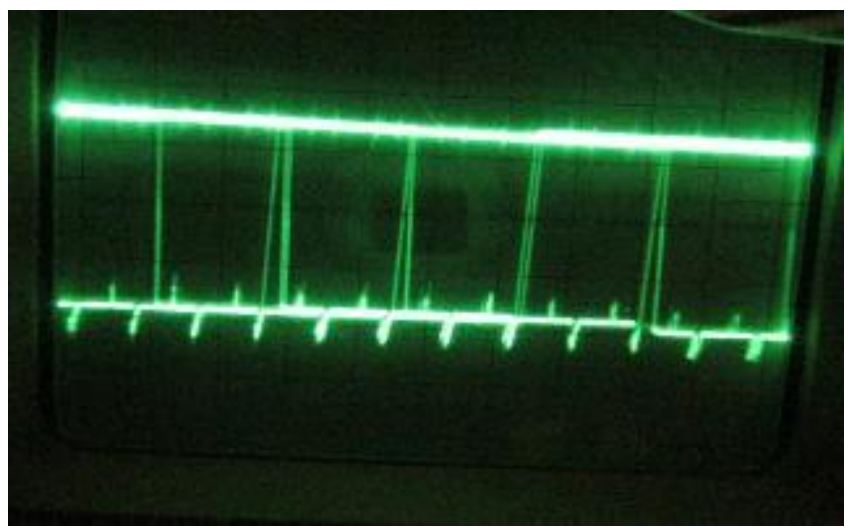

Fig. 17. Diagram voltage - time. Speed 600RPM. The interval between the first and second interval represent is a rotation of the flywheel.
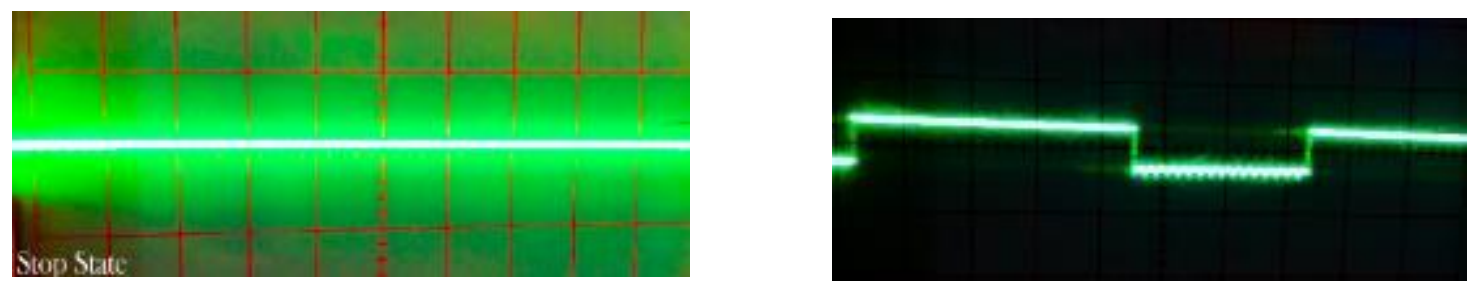

Fig. 18. Diagram voltage - time. Output of PVDF in speed 200RPM 


\subsection{Harvesting energy and voltage generation}

The tension in the piezoelectric element at 400RPM was $100 \mathrm{MPa}$ and the strain was 0.002 (Fig. 20) the test at engine speeds of 200RPM, 300RPM, 400RPM and 600RPM was repeated, but due to the volume of data, results of other tests are not mentioned in detail and are plotted on the given diagram.

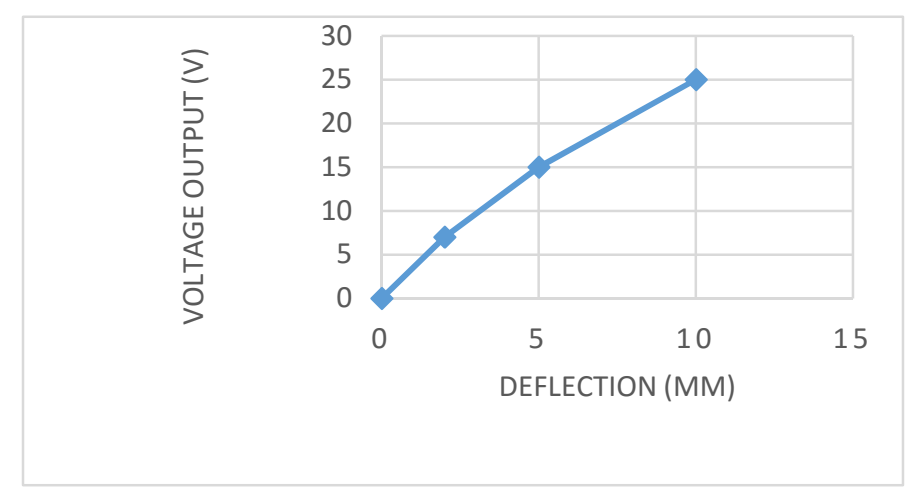

Fig. 19. Chart voltage changes according to the amount of deviation PVDF. Using a charge amplifier to obtain "open-circuit" voltage sensitivity, the output was measured for controlled tip deflections applied to the sensor (supported by its Crimped contacts as described above). $\mathbf{2}$ $\boldsymbol{n} \boldsymbol{n}$ Deflection was sufficient to generate about $7 \mathrm{~V}$. Voltages above $70 \mathrm{~V}$ could be generated by bending the tip of the sensor through 90 .

Due to very low piezoelectric voltage of deformation to produce at the examination of amplifier is used. The results of static analysis in software showed, the displacement of the beam is $7 \mathrm{~mm}$ and PVDF 4-5 $\mathrm{mm}$ that the piezoelectric output of 25 volts is obtained (Fig. 21). In experimental testing (400RPM) in the PVDF, displacement was approximately $5 \mathrm{~mm}$. In accordance with Fig. 19 should generate in piezoelectric, about 15 volts. (Fig. 19 and 22 is taken from the catalog of the manufacturer company with code: LDT0-028K) 


\subsection{Analysis PVDF and voltage generation}
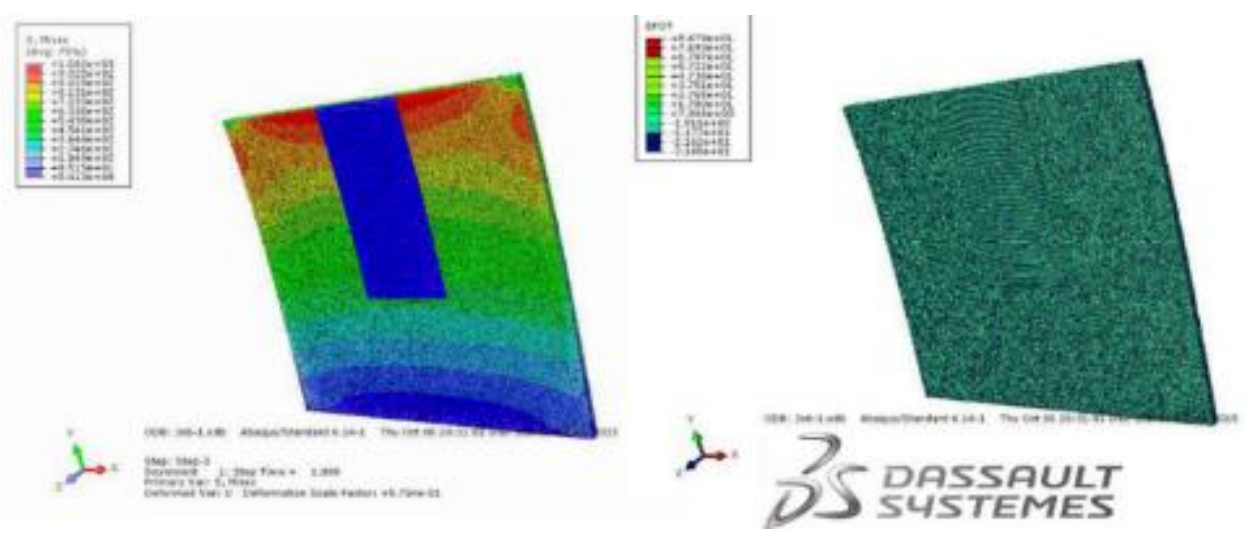

Fig. 20. The stress contours - analysis PVDF on CK75. (Static analysis - FEM simulation)

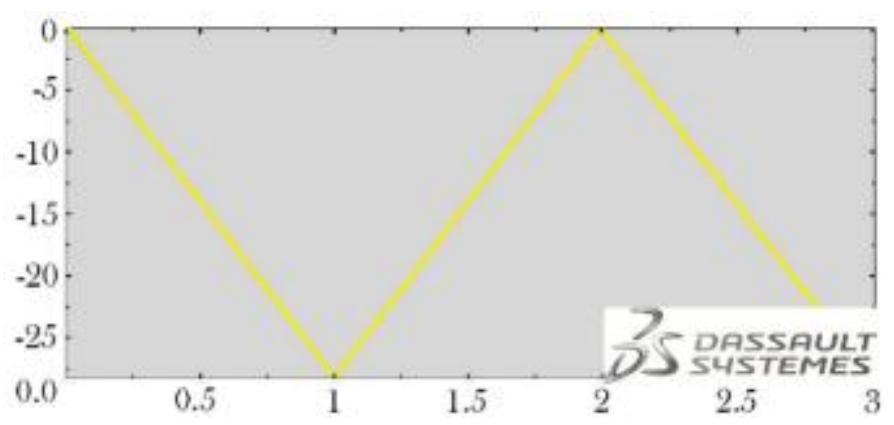

Fig.21. Electric potential - Time(s), static analysis

\section{PIEZOELECTRIC (PVDF) BEHAVIOR IN DIFFERENT SPEEDS}

With the crimped contacts pushed through a printed-circuit board, the PVDF was soldered carefully in place to anchor the sensor. A charge amplifier was used to detect the output signal as vibration from a shaker table was applied (using a charge amplifier allows a very long measurement time constant and thus allows the "open-circuit" voltage response to be calculated). Small masses (approximately 0.26g Increments) were then added to the tip of the sensor, and the measurement repeated. Results are shown in Table 1 and the Overlaid plots in Fig. 22. Without adding mass, the PVDF shows a resonance around $180 \mathrm{~Hz}$. Adding mass to the tip reduces the resonance frequency and increases "baseline" sensitivity (Table 4). 


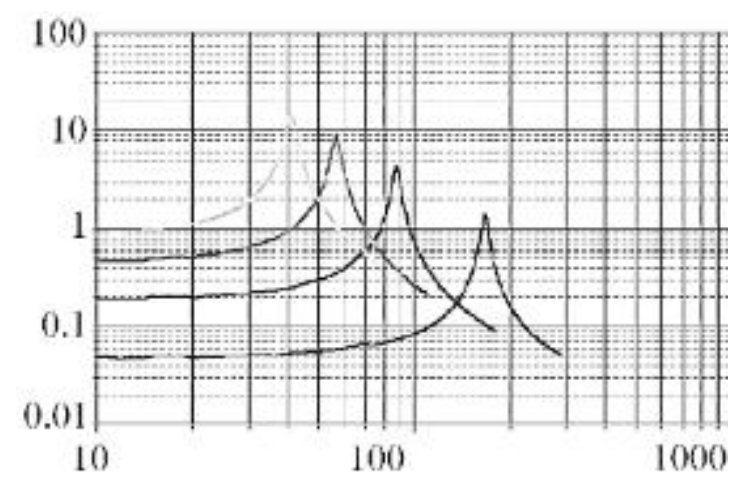

Fig.22. PVDF sensitivity: Effect of added mass. The vertical axis is sensitivity $(\boldsymbol{V} / \boldsymbol{g})$ and the horizontal axis is frequency $(\mathrm{Hz})$

Table 4. PVDF as vibration sensor

\begin{tabular}{ccccc}
\hline $\begin{array}{c}\text { Added } \\
\text { Mass }\end{array}$ & $\begin{array}{c}\text { Baseline } \\
\text { Sensitivity }\end{array}$ & $\begin{array}{c}\text { Sensitivity at } \\
\text { Resonance }\end{array}$ & $\begin{array}{c}\text { Resonant } \\
\text { Frequency }\end{array}$ & $\begin{array}{c}+3 \mathrm{Db} \\
\text { Frequency }\end{array}$ \\
\hline 0 & 50 & 1.4 & $180 \mathrm{~Hz}$ & $90 \mathrm{~Hz}$ \\
1 & 200 & 4 & $90 \mathrm{~Hz}$ & $45 \mathrm{~Hz}$ \\
2 & 400 & 8 & $60 \mathrm{~Hz}$ & $30 \mathrm{~Hz}$ \\
3 & 800 & 16 & $40 \mathrm{~Hz}$ & $20 \mathrm{~Hz}$ \\
\hline
\end{tabular}

\subsection{Forecast for resonant frequency}

According to Fig. 12, the dimensions of Ck75 beam are $14 \mathrm{~mm} \times 40 \mathrm{~mm}$, the suspended or like added mass to piezoelectric end is $4.71 \mathrm{gr}$. (According to dimensions and density of CK75 sheet). Flywheel vibrations used as shaker and suspended cantilever is (14 $\mathrm{mm} \times 40$ $\mathrm{mm}$ ) as acceleration (added mass).

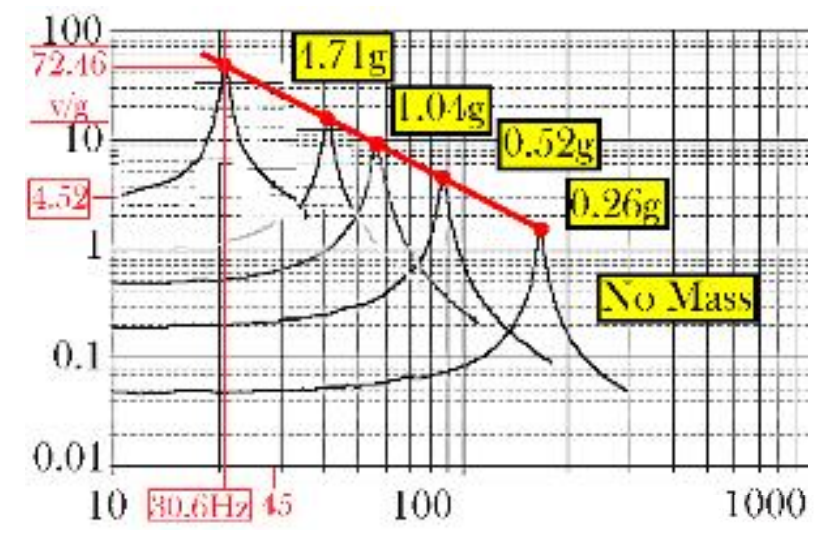

Fig. 23. Resonant frequency for PVDF in testable conditions. Red points are resonant frequency in added different mass. New diagram (for $4.71 \mathrm{gr}$ ) obtained from graphic drawing. 
Table 5. Find resonant frequency and baseline sensitivity in testable conditions and adjust or accord with the catalog of the manufacturer company.

\begin{tabular}{|c|c|c|c|}
\hline $\begin{array}{l}\text { Added } \\
\text { Mass(gr) }\end{array}$ & $\begin{array}{l}\text { Baseline } \\
\text { Sensitivity }\end{array}$ & $\begin{array}{l}\text { Sensitivity at } \\
\text { Resonance }\end{array}$ & $\begin{array}{l}\text { Resonant } \\
\text { Frequency }\end{array}$ \\
\hline 0 & 50 & $1.4 \div::$ & $180 \mathrm{~Hz}$ \\
\hline 0.26 & 200 营祀 & 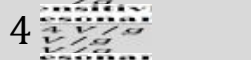 & $90 \mathrm{~Hz}$ \\
\hline 0.52 & 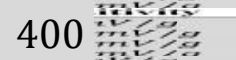 & 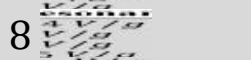 & $60 \mathrm{~Hz}$ \\
\hline 1.04 & 800 : & 16 得 & $40 \mathrm{~Hz}$ \\
\hline 4.71 & $3616: V / g$ & $72.46=\ldots$ & $30.6 \mathrm{~Hz}$ \\
\hline
\end{tabular}

(Resonant frequency in $4.71 \mathrm{gr}(30.6 \mathrm{~Hz})$, and sensitivity at resonance $(72.46 \mathrm{~V} / \mathrm{g})$ obtained from Fig. 23. According to Fig. 21, voltage generation is $25 v$.

Red section is sensitivity at resonance and yellow section is speed of electrical engine in experimental test. (20 Hz is 400RPM). All of the results in this section are approximate.

\subsection{Resonant frequency in CK75}

$$
\omega n=\sqrt{ } k m(5)
$$

" $E "$ is $210 \times 106 \mathrm{MPa}$ and " $I "$ is $12 \mathrm{bh} 3$ for it. ( $I=5 \times 10-9$ and $L=40 \mathrm{~mm}$ according to Fig. 12 ) For dimensions of $40 \mathrm{~mm} \times 40 \mathrm{~mm} \times 1 \mathrm{~mm}$ in CK75, "m" is $12.56 \mathrm{gr}$. As a result, resonant frequency for CK75 is $31.04 \mathrm{~Hz}$. According to Table 5, resonant frequency for testable conditions was $30.6 \mathrm{~Hz}$. Frequency in testable conditions (400RPM) is $20 \mathrm{~Hz}$ (Inverter - Fig. 8). Anyway, this mechanism in 30 to $31 \mathrm{~Hz}$ frequency, is dangerous (or in $600-605 \mathrm{RPM}$ ). Resonant frequency of PVDF with added mass 4.71 , is equal about resonant. If automotive engine, work with 600RPM or more, we observe that voltage generation decrease but, this mechanism has similar functions of revolution sensor.

\subsection{Compare and analysis of several samples in other researches}

a. The first research: The experiment was carried out using four different proof masses; 0, 2.4 gr, $4.8 \mathrm{gr}$ and 7.2 gr. Fig. 25.a shows the voltage generated for the first two modes with different proof masses. From Fig. 25.a, it can be observed that the voltage produced at the first mode increases with the weight of the proof mass. Also, the first natural frequency decreases as the weight of the proof mass increased. Hence, the proof 
mass has the ability to tune the natural frequency of the beam. The experimental results are then compared with the analytical simulation [13]

b. The second research: Note that the base acceleration in both FRFs is normalized with respect to the gravitational acceleration, $g=9.81 \mathrm{~m} / \mathrm{S}^{2}$ and the arrows in each set of FRFs indicate the direction of increasing load resistance. Both the voltage and the tip velocity predictions are highly inaccurate especially in terms of the resonance frequency when $N=1$. If the number of modes in the assumed-modes solution is increased to $\mathrm{N}=$ 3, the predictions are improved substantially as observed in Fig. 25.b (see also Table 7) [14]

Table 7. Assumed-modes predictions of the fundamental short-circuit and open-circuit resonance frequencies of the voltage FRF (compared against the analytical and the experimental results) [14]

\begin{tabular}{lll}
\hline & $\begin{array}{l}\text { Short-circuit } \\
\text { resonance frequency }[\mathrm{Hz}]\end{array}$ & $\begin{array}{l}\text { Open-circuit } \\
\text { resonance frequency [Hz] }\end{array}$ \\
\hline Experimental & 502.5 & 524.7 \\
Analytical & 502.6 & 524.5 \\
Assumed-modes $(\mathrm{N}=1)$ & 523.8 & 555.3 \\
Assumed-modes $(\mathrm{N}=3)$ & 503.2 & 525.5 \\
\hline
\end{tabular}

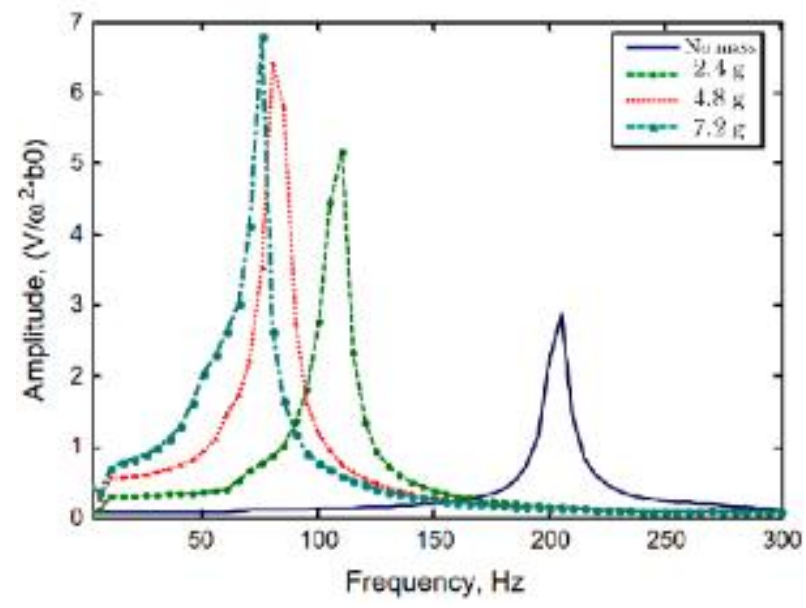

(a)

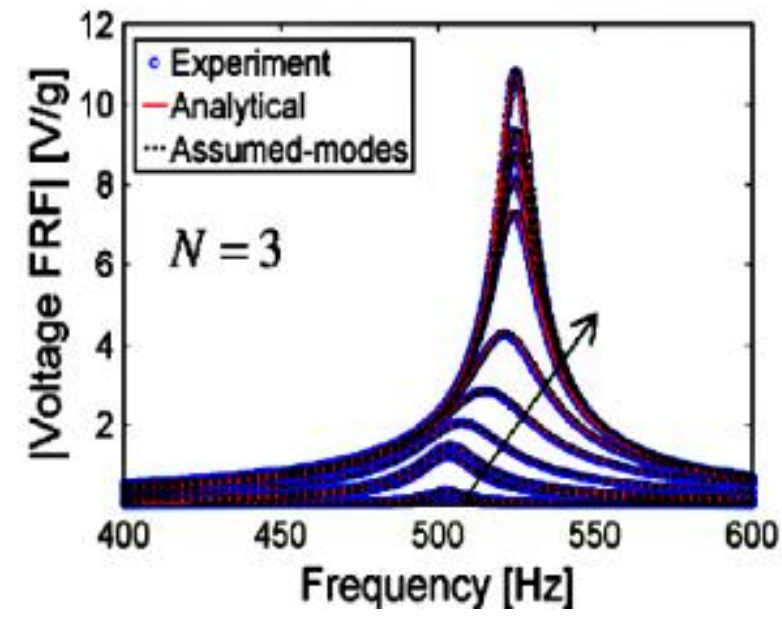

(b)

Fig. 25. (a) Output voltage from experimental for PZT with different mass - close up for 1st natural frequency. (b) Voltage FRFs. PZT-5H piezoelectric elements [13], [14].

In all of the testes and analyses, piezoelectric elements (PZT, PVDF...) against increases acceleration with added mass in vibrations, have a similar behavior[12] , [14]. This similar behavior is different in resonant frequency and sensitivity at resonance with added different 
masses in different frequency $[15,16,17]$.

\section{CONCLUSION}

These tests are quite tentative and out of reality and only were to prove the hypothesis. To get closer to reality, one must select an electric motor with high-speed 2000RPM, and such design beam, that can withstand a period of more than 2000RPM and remain in elastic phase. Piezoelectric element behavior at higher stresses was not tested from the piezoelectric elements Can be used on both sides of the beam (PVDF), so they will have twice energy harvesting (as shown in Fig. 4). The output signals from piezoelectric are easily transferable to the ECU so that by putting a piezoelectric amplifier circuit, its output voltage to 12 volts (According to the vehicle power supply). This mechanism that uses piezoelectric can be easily revolution sensor vehicles .Because of the contact between the sensor (the PVDF on beam) and flywheel teethes, very high signal accuracy and there is no possibility of rejection signal interruption. According to the patterns we observe the voltage changes that errors and ramps is much less than inductive revolution sensors. Due to physical interference, relatively high sound waves emitted from this mechanism, but Compared with that sound waves emitted from motor vehicles is negligible, which can be minimized with sound insulation. The graphs shown are all based on voltage changes, these changes are the main cause of electricity current. As can be seen in the difference voltage signal is interrupted, than output of the inductive sensor function is much clear. The software analyzes the voltage of 25 volts (Fig. 21) and 15 volts was obtained in the experimental tests. This difference is due to devices such as oscilloscopes, inverters, etc.

\section{ACKNOWLEDGMENTS}

Thanks to Amir Atarod B.Sc. in islamic azad universty, najafabad branch and Iran Khodro for information about the revolution sensor and flywheel and thanks to the electric-power workshop officials in Islamic Azad University, Najafabad Branch. Mr. Shirani who cooperation in the design and construction of electrical circuits. 


\section{REFERENCES}

[1] Vigliani A, Galvagno E, Velardocchia M. A model for a flywheel automatic assisted manual transmission. Mechanism and Machine Theory .2009. 44 (2009) 1294-1305.

[2] Duan F, Guo H, Zhang J. Blade resonance parameter identification based on tip-timing method without the once-per revolution sensor. Mechanical Systems and Signal Processing .2016. 66-67(2016)625-639.

[3] Stanton S C, McGehee C, Mann Brian P. Nonlinear dynamics for broadband energy harvesting: Investigation of a bistable piezoelectric inertial generator. Physica. 2010. D 239 (2010) 640-653.

[4] JunYang L, FeiFu Q. Visualization studies of the spray from swirl injectors under elevated ambient pressure. Aerospace Science and Technology. 2015. 47 (2015) 154-163.

[5] Lee C, Liu H, Dhakar L, Tay F.E.H. A new energy harvester design for high power output at low Frequencies. Sensors and Actuators. 2013. A 199 (2013) 344- 352.

[6] Lee C, Liu H, Kobayashi T, Tay C J, Quan C. Piezoelectric MEMS-based wideband energy harvesting systems using a frequency-up-conversion cantilever stopper. Sensors and Actuators. 2012. A 186 (2012) 242- 248.

[7] Erturk A, Inman D J. Broadband piezoelectric power generation on high-energy orbits of the bistable Duffing oscillator with electromechanical coupling. Journal of Sound and Vibration. 2011. 330 (2011) 2339-2353.

[8] Ferrari M, Bau M, Guizzetti M, Ferrari V. A single-magnet nonlinear piezoelectric converter for enhanced energy harvesting from random vibrations. Sensors and Actuators. 2011. A 172 (2011) 287- 292.

[9] Uzun Y, Kurt E. the effect of periodic magnetic force on a piezoelectric energy harvester. Sensors and Actuators. 2013. A 192 (2013) 58- 68.

[10] Yu H, Zhou J, Yi X, Wu H, Wang W. A hybrid micro vibration energy harvester with power management circuit. Microelectronic Engineering. 2014. xxx (2014) xxx-xxx.

[11] Liu Y, Higuchi T , Fung R. a novel precision positioning table utilizing impact force of spring-mounted piezoelectric actuator-part I: experimental design and results. Precision Engineering. 2003. 27 (2003) 14-21.13. 
[12] Zheng X J, Zhou L, Deng S F, Zhao J H, Peng S T, Zhang Y, Wang X Y, Cheng H B. A model for the energy harvesting performance of shear mode piezoelectric cantilever. Sensors and Actuators. 2012. A 179 (2012) 185- 192.

[13] Erturk A. Assumed-modes modeling of piezoelectric energy harvesters: Euler-Bernoulli, Rayleigh, and Timoshenko models with axial deformations. Computers and Structures. 2012. 106-107 (2012) 214-227.

[14] Fakhzan M.N, Muthalif A G A. Harvesting vibration energy using piezoelectric material: Modeling, simulation and experimental verifications. Mechatronics. 2013. 23 (2013) 61-66.

[15] Alshareef H N, Al Ahmad M. Energy harvesting from radio frequency propagation using piezoelectric cantilevers. Solid-State Electronics. 2012. 68 (2012) 13-17.

[16] Romani A, Tartagni M, Paganelli R P. Fast and Reliable Modeling of Piezoelectric Transducers for Energy Harvesting Applications. Procedia Engineering. 2011. 25 (2011) 1345 - 1348. Proc. Eurosensors XXV, September 4-7, 2011, Athens, Greece.

[17] Zhu M, Edkins S. Analytical modelling results of piezoelectric energy harvesting devices for self-power sensors/sensor networks in sstructural health monitoring. Procedia Engineering. 2011. 25 (2011) 195 - 198. Proc. Eurosensors XXV, September 4-7, 2011, Athens, Greece.

\section{How to cite this article:}

Mahmoudi M, Vatankhahan F, Totian H, Fouladgar, Ghassemi A. Determining a piston's top dead center (tdc) in an automobile using installed piezoelectric on a vibrating beam. Appl. Sci., 2016, 8(3S), 1321-1339. 